\title{
REMARKS ON THE PAPER "MASS AND ENERGY-CAPITAL CONSERVATION EQUATIONS TO FORECAST MONTHLY OIL PRICE"'
}

\author{
Fabio Gori \\ University of Rome “Tor Vergata”, Via del Politecnico 1, 00133 Rome, Italy \\ Fax +39-06-72597129, E-mail: fammannati@yahoo.com
}

\begin{abstract}
The mass and energy-capital conservation equations have been used at the beginning of 2013 to forecast the monthly oil price up to December 2013. The approach of the interest rates has employed an interest rate equal to the arithmetic average between the prime and the discount rates. The present short communication comments the comparison between the forecast made during the middle of the 2013 and the real oil prices, as registered today, at the beginning of 2014.
\end{abstract}

\section{Keywords:}

previous forecast from March to December 2013;

verification with real data of February 2014;

seven months period of forecast.

\section{INTRODUCTION}

The forecast of the price of non-renewable resources is an important issue in economic planning and the Hotelling rule suggests that their price increases exponentially with the product of time and interest rate of capital [1-2]. A first generalization of the Hotelling rule [3] has shown that the rate of exponential increase is the product of the time and the difference between the inflation and the extraction rates. A second generalization of the Hotelling rule [4] introduced the difference between the interest rate of the capital, prime or discount rate, and the extraction rate, showing that the price can increase or decrease with time, also passing throughout a maximum or a minimum, differently from what happens with the Hotelling rule, where the price is linked only to the interest rate of the capital, usually positive. The energy supply curve of non-renewable energy resources, i.e. price versus consumption, has be constructed introducing new parameters of evaluation, [5]. The real annual mass flow rate of oil extraction in the world from 1965 to 2006 has been presented and discussed in [6].

The approach of the interest rates, [3-6], has been recently applied to periods with negative inflation rates, confirming the robustness of the present theory and identifying the extremes of the forecast in the assumption of the interest rates, e.g. prime or discount rates. The preliminary results of [7] have been confirmed in [8] for a more wide variation of the discount rates, showing the 
importance of the two parameters, "Critical Initial Price of Sold resources", CIPS, which depends on the initial price of the extracted resources, on the interest rate of the non-extracted resources, and the difference between the "Price Increase Factor of Extracted resources", PIFE and the "Price Increase Factor of Selling resources", PIFS, and the "Critical Initial Price Extreme of Selling resources", CIPES, which depends on the initial price of the extracted resources, on the interest rate of the non-extracted resources, and on PIFS.

The present short communication is aimed to comment the forecast presented in [9] up to December 2013.

\section{DISCUSSION}

At the time of the submission of the paper [9] the following data were available from January to May 2013: the real monthly oil prices, inflation, prime and discount rates, while extraction rates were available only for January and February. The real data available at the time of the submission of the paper [9] are reported in bold in Table 3 of [9] and in Table 1 of this communication, along to the parameters used in the present theoretical approach and the forecast obtained. The statistical data are taken from [10-13].

The first column of Table 1 reports the month under investigation, the second one the average oil price of the previous month, the third one the oil extraction rate registered at the end of the previous month, the fourth one the inflation rate at the end of the previous month, the fifth one the arithmetic average between prime and discount rate, respectively 3.25 and 0.5 , of the previous month, from the sixth to the ninth column the parameters of the present theory, i.e. PIFE, PIFS, CIPS and CIPES, evaluated according to the data of the previous month, the tenth one the category of the forecast of the present theory, as discussed in [9], the eleventh one the price forecasted after 31 days, i.e. at the end of the month, and the twelfth one the number of days after which a maximum is present.

Table 3 of [9] reported in the tenth column: the forecast obtained in January and February with the real monthly data; the forecast obtained from March until May by using the average extraction rate of January and February; the forecast obtained from June until December 2013 by using the data of May 2013. These last forecast were reported in Fig. 12 of [9], with the conclusion of an increase of the oil price from June until September 2013, when was forecasted a maximum of 20.46 (US day/GJ), and then a decrease to 16.94 (US day/GJ) in December 2013.

Figure 1 is an updated version of Fig. 12 of [9] where the real oil prices from June to December 2013, according to the statistical data of [10] at the day of February $10^{\text {th }} 2014$, are added and reported as monthly average at the beginning of the following month. The real monthly oil price during 2013 increased from January to February, decreased until May, increased up to a 
maximum in September and finally decreased until December 2013. The agreement between the forecast announced in Table 3 of [9] and the real oil price registered at the day of February $10^{\text {th }}$, 2014 , is extremely good.

The real oil price and the economic data, extraction and inflation rates, are finally reported in Table 1 from January to December 2013, according to the statistical data of [10], at the day of February $10^{\text {th }}, 2014$. The monthly oil prices are shifted of one month because the oil price at the beginning of a month is the average oil price of the previous one. The monthly parameters and the forecast, obtained with the interest rate equal to $r_{E}=1.875$, i.e. the arithmetic average of the prime and the discount rate, are also reported in the following columns. The monthly forecast shows some oscillations from February to July, a following increase up to a maximum in September and a decrease until December 2013.

Figure 2 reports the oil price forecasted monthly from January to December 2013, including the forecast obtained with the prime and the discount rate, not reported in Table 1, showing a relative maximum at the beginning of September 2013 and a decrease up to the beginning of December 2013. The oil price forecasted with the average interest rate, 1.875, reported in Table 1 is in good agreement to the real evolution.

\section{CONCLUSIONS}

The method of using the mass and the energy-capital conservation equations to forecast the monthly oil price has been verified. The present theory assumes inflation rate as interest rate of the non-extracted oil, prime or discount rate as the extremes interest rates of the selling oil. The use of the extraction rate of oil into the mass and energy conservation equations allows the introduction of four parameters which are important in the forecast. The forecast of the oil price from May until December 2013 has been carried out by using the unknown economic parameters as the average values of those of the first two months of 2013. The present short communication remarks the general good agreement between the forecast of the oil price in a time period of seven months, besides the monthly forecast, and the real oil price evolution.

\section{REFERENCES}

[1] H. Hotelling, The Economics of Exhaustible Resources, Journal of Political Economy, 39 (1931) 137-175.

[2] P.S. Dasgupta, G.M. Heal, Economic Theory and Exhaustible Resources, Cambridge University Press, Cambridge, UK, 1979.

[3] F. Gori, Mass and Energy-Capital Conservation Equations to Study the Price Evolution of nonRenewable Energy Resources. Part I-Generalization of the Hotelling Rule. Applied Thermal Engineering, 26 (2006) 1746-1750. 
[4] F. Gori, Mass and Energy-Capital Conservation Equations to Study the Price Evolution of nonRenewable Energy Resources. Part II -Extension to resources sold to the market. Applied Thermal Engineering, 26 (2006) 1751-1770.

[5] F. Gori, Mass and Energy-Capital Conservation Equations to Study the Price Evolution of NonRenewable Energy Resources. Part III-Energy supply curve. Applied Thermal Engineering, 29 (2009) 2172-2186.

[6] F. Gori, Mass and Energy-Capital Conservation Equations for the Time Evolution of NonRenewable Energy Resources. In: J. Evgova, O. Kostadinov, (Eds.), Thermal Engineering Research Developments, Nova Science Publishers Inc., New York, USA, 2009, Chapter 5.

[7] F. Gori, Forecasting the Time Evolution of Oil Price with Negative Inflation Rate. Proceedings of ASME 2012 International Mechanical Engineering Conference and Exhibition, November 9-15, Houston, Texas, USA, 2012, Paper 86729.

[8] F. Gori, Forecasting the Time Evolution of the Oil Price During Months of Negative Inflation Rate. Journal of Energy Resources Technology, 135/1 (2013) 011602, 1-8.

[9] F. Gori, Mass and energy-capital conservation equations to forecast monthly oil price. Applied Thermal Engineering 61 (2013) 623-632.

[10] Economagic.com, "Price of West Texas Intermediate Crude; Monthly NSA, Dollars Per Barrel,“www.economagic.com/em-cgi/data.exe/var/west-texas-crude-long, 28th June, 2013.

[11] Capital Professional Services, LLC., "Historical Inflation Rate," www.inflationdata.com /Inflation/Inflation_Rate/HistoricalInflation.aspx, $28^{\text {th }}$ June, 2013.

[12] Economagic.com, "Discount Window Borrowing Rate," www.economagic.com/emcgi/data.exe /fedbog/dwb, $28^{\text {th }}$ June, 2013.

[13] FedPrimeRate.com, "Prime Interest Rate History," www.fedprimerate.com /wall_street_journal_prime_rate_history.htm, $28^{\text {th }}$ June, 2013. 


\section{CAPTIONS TO TABLES}

Table 1 - Oil price, extraction rate, interest rates and parameters used for the forecast from January until December 2013. The interest rate $r_{E}$ is the average 1.875 . 


\section{CAPTIONS TO FIGURES.}

Figure 1. Oil price (US\$ day/GJ) forecasted with prime, discount and average rates (\%/annum), monthly from January to May and during the period of seven months from June until December 2013.

Figure 2. Oil price (US\$ day/GJ) forecasted monthly with prime, discount and average rates, (\%/annum), from January until December 2013. 
Table 1 - Oil price, extraction rate, interest rates and parameters used for the forecast from January until December 2013. The interest rate $r_{E}$ is the average 1.875 .

\begin{tabular}{|c|c|c|c|c|c|c|c|c|c|c|c|}
\hline $\mathrm{Y} / \mathrm{M}$ & \begin{tabular}{|c|} 
US\$ \\
Day/GJ
\end{tabular} & $\begin{array}{c}\alpha \\
\text { (month) }\end{array}$ & $\begin{array}{c}\mathrm{r}_{\mathrm{N}} \\
\text { (infl) }\end{array}$ & $\begin{array}{c}\mathrm{r}_{\mathrm{E}} \\
\text { (aver) }\end{array}$ & PIFE & PIFS & CIPS & CIPES & $\begin{array}{l}\text { Forecast, } \\
\text { Category, }\end{array}$ & $\begin{array}{c}\text { ps } \\
\text { (31 days) }\end{array}$ & $\begin{array}{c}\mathrm{Tm} \\
\text { (days) }\end{array}$ \\
\hline $2013 / J$ & 15.38 & \begin{tabular}{|c|}
-0.953 \\
\end{tabular} & 1.59 & 1.875 & 2.54 & 2.83 & 92.09 & 9.28 & $\uparrow 1-\mathrm{B}$ & 18.16 & 116. \\
\hline $2013 / \mathrm{F}$ & 16.51 & 0.253 & 1.98 & 1.875 & 1.73 & 1.62 & -313.34 & 20.29 & $\downarrow 1-\mathrm{C}$ & 15.87 & \\
\hline $2013 / \mathrm{M}$ & 16.62 & \begin{tabular}{l|}
-0.075 \\
\end{tabular} & 1.47 & 1.875 & 1.55 & 1.95 & 58.88 & 12.23 & $\uparrow 1-\mathrm{B}$ & 16.78 & 80.6 \\
\hline $2013 / \mathrm{A}$ & 16.22 & 1.013 & 1.06 & 1.875 & 0.05 & 0.86 & 20.88 & 19.74 & $\downarrow 1-\mathrm{C}$ & 15.77 & \\
\hline $2013 / \mathrm{M}$ & 16.05 & 0.331 & 1.36 & 1.875 & 1.03 & 1.54 & 43.64 & 14.55 & $\uparrow 1-\mathrm{B}$ & 16.71 & 49.7 \\
\hline $2013 / J$ & 16.53 & -0.090 & 1.75 & 1.875 & 1.84 & 1.96 & 233.73 & 14.87 & $\uparrow 1-\mathrm{B}$ & 16.81 & 24. \\
\hline $2013 / J$ & 16.70 & 1.015 & 1.96 & 1.875 & 0.95 & 0.86 & -420.75 & 41.57 & $\downarrow 1-C$ & 16.39 & \\
\hline $2013 / \mathrm{A}$ & 18.25 & -0.317 & 1.52 & 1.875 & 1.84 & 2.19 & 79.54 & 12.88 & $\uparrow 1-\mathrm{B}$ & 19.52 & 91.8 \\
\hline $2013 / \mathrm{S}$ & 18.58 & -0.181 & 1.18 & 1.875 & 1.36 & 2.06 & 31.46 & 10.64 & $\uparrow 1-\mathrm{B}$ & 19.89 & 250.26 \\
\hline $2013 / \mathrm{O}$ & 18.53 & -0.181 & 0.96 & 1.875 & 1.14 & 2.06 & 18.39 & 8.18 & $\uparrow 1-\mathrm{B}$ & 19.20 & 985.8 \\
\hline $2013 / \mathrm{N}$ & 17.53 & -0.181 & 1.24 & 1.875 & 1.42 & 2.06 & 31.95 & 9.87 & $\uparrow 1-\mathrm{B}$ & 17.47 & 200.14 \\
\hline 2013/D & 16.36 & -0.181 & 1.50 & 1.875 & 1.68 & 2.06 & 68.08 & 12.42 & $\uparrow 1-\mathrm{B}$ & 17.71 & 83.9 \\
\hline
\end{tabular}




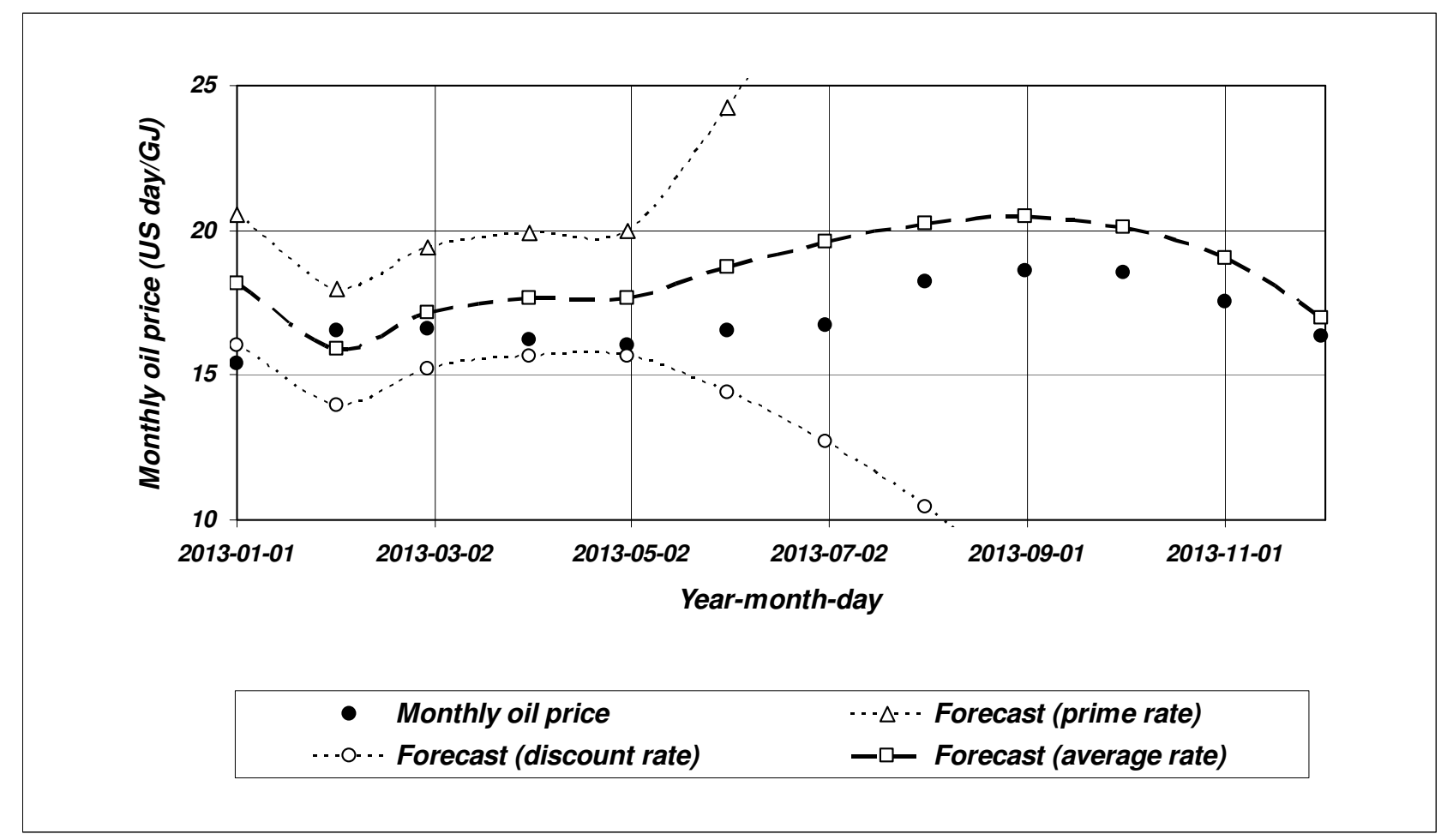

Figure 1. Oil price (US\$ day/GJ) forecasted with prime, discount and average rates (\%/annum), monthly from January to May and during the period of seven months from June until December 2013. 


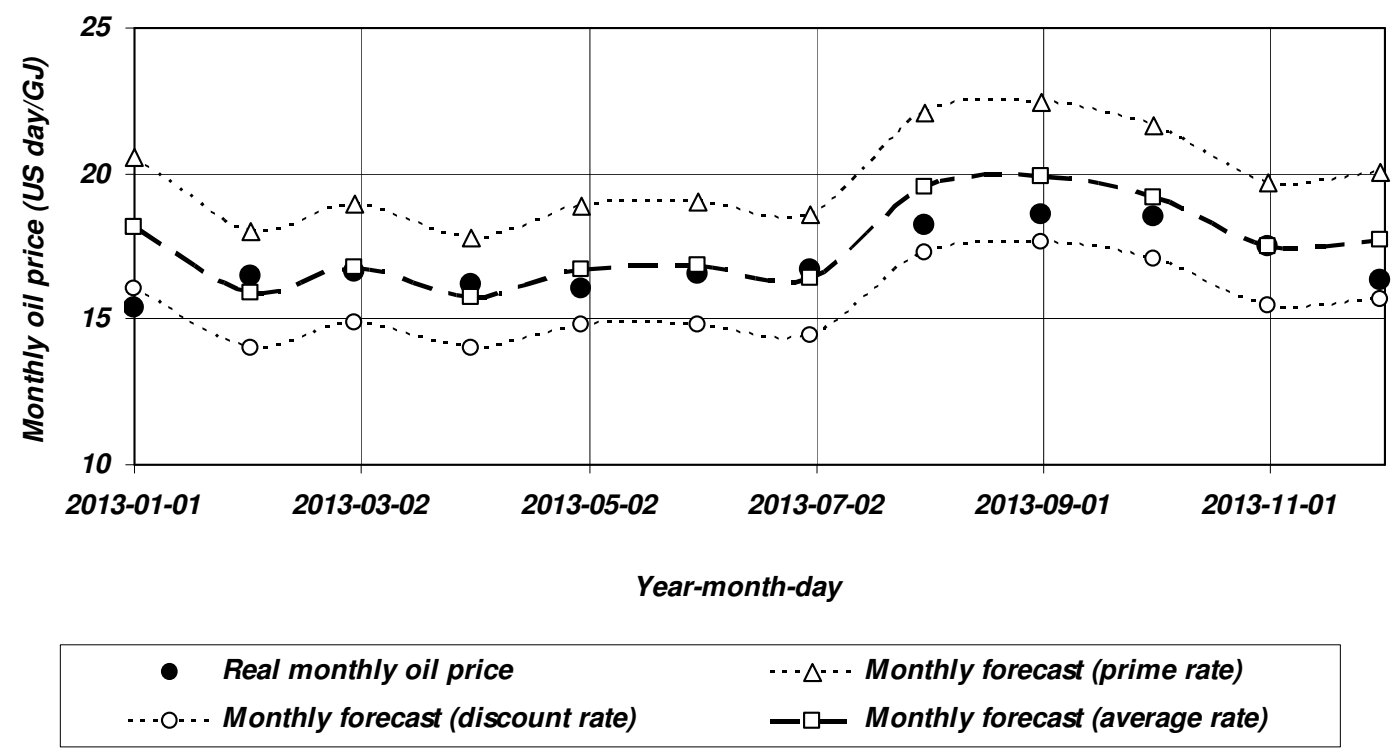

Figure 2. Oil price (US\$ day/GJ) forecasted monthly with prime, discount and average rates, (\%/annum), from January until December 2013. 